\title{
CATÁSTROFE E SOBREVIVÊNCIA EM HEART OF DARKNESS
}

http://dx.doi.org/10.11606/issn.2237-1184.v0i30p127-139

Sandra Guardini Vasconcelos ${ }^{\mathrm{I}}$

\section{RESUM0}

$\mathrm{O}$ artigo discute a leitura que Antonio Candido propõe para "The Secret Sharer" e Lord Jim, de Joseph Conrad, a partir do que o crítico argumenta serem seus temas mais reveladores ("o isolamento, a ocasião, o homem surpreendido") e do modo como a figuração do "ser em crise" se projeta na forma do conto e do romance. Sua análise e interpretação fornecem pistas produtivas para ler Heart of Darkness, outra obra central do autor britânico de origem polonesa.

\section{ABSTRACT}

This article discusses Antonio Candido's reading of Joseph Conrad's "The Secret Sharer" and Lord Jim, based on what the critic argues are their most telling themes ("isolation, the occasion, the surprised man") and on how the configuration of "the human being in a state of crisis" is projected on the form of the short story and the novel. His analysis and interpretation provide productive clues to read Heart of Darkness, another central work by the Polish-British author.

\section{PALAVRAS-CHAVE:}

Antonio Candido; Joseph Conrad; Impressionismo; forma literária; processo histórico.

\section{KEYWORDS}

Antonio Candido;

Joseph Conrad;

Impressionism;

literary form;

historical process.

\footnotetext{
'Universidade de São Paulo, São Paulo, São Paulo, Brasil.
} 


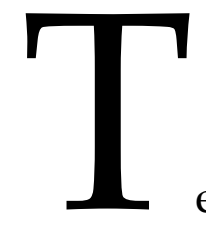

endo como versão preliminar o artigo "Exotismo e aventura em Conrad", publicado no Suplemento Literário de O Estado de S. Paulo em junho de 1957, "Catástrofe e sobrevivência" toma para análise o conto "The Secret Sharer" (1909) ${ }^{1}$ e o romance Lord Jim (1900) como textos exemplares do conjunto da obra do escritor britânico de origem polonesa pela recorrência, neles, de "alguns dos seus temas mais reveladores: o isolamento, a ocasião, o homem surpreendido, dispostos à volta da preocupação fundamental com o ato, em que para ele [Conrad] se espelha realmente o homem" (CANDIDO, 1971, p. 62). A leitura de Antonio Candido enfeixa vários passos, que compreendem um breve apanhado da recepção crítica (parte I) a que se soma uma apresentação geral dos principais traços característicos da produção conradiana (parte II); um comentário iluminador a respeito das linhas mestras de uma concepção que explora a figura do "ser em crise", com rebatimento na forma e nas escolhas estilísticas, para dar voz a preocupações de ordem ética e moral (parte III); a presença do duplo e da divisão em "The Secret Sharer" (parte IV); a leitura cerrada de Lord Jim (partes V e VI), a qual retoma as questões levantadas anteriormente $\mathrm{e}$ as analisa tal como se configuram nesse romance.

Sobressaem, nesse percurso, os movimentos do leitor no sentido da incorporação, evidente a essa altura, de diferentes aportes para dar conta de seu objeto, seja o recurso à crítica temática, a dados biográficos pertinentes, à visão ideológica do escritor, mas sobretudo - e aqui desponta o traço essencial do caminho crítico de Antonio Candido - a precipitação do conteúdo em forma, para o que a técnica narrativa é submetida a um exame atento e minucioso.

Narrativas que tematizam um momento crucial de ampliação dos horizontes do romance, em que se abre espaço para a alteridade da vida colonial, do sofrimento e da exploração coloniais, os dois textos de Joseph Conrad impõem ao escritor a necessidade de encontrar uma nova forma a fim de dar conta de novos tipos de experiência, o que irá implicar a dissolução de uma visão realista da vida cotidiana e a adoção de um modo de representação oblíquo e indireto. À dificuldade de decodificar, ou compreender, a experiência de alteridade corresponderá uma forma que investe no borramento, na obscuridade, na imprecisão, à maneira da arte impressionista, cujos procedimentos Conrad tomará emprestado. Em "The

1 "The Secret Sharer" foi publicado pela primeira vez em 1910 na Harper's Magazine (em 2 partes) e depois incluído na coletânea de contos Twixt Land and Sea: Tales (1912). Em nota bibliográfica, Candido informa que a versão em Tese e antítese é texto inédito, cujas ideias centrais haviam sido publicadas no artigo "Aventura e exotismo" no Suplemento Literário d'O Estado de S. Paulo, em 1957. 
Secret Sharer", um jovem capitão pela primeira vez no comando de um navio narra seu inesperado e surpreendente encontro noturno com um assassino foragido do Sephora, o que o leva inexplicavelmente a agir contra seu dever e a transgredir o código de conduta dos homens do mar. Como explica Albert J. Guerard, trata-se de uma situação que Conrad irá dramatizar inúmeras vezes: "o ato de identificação compassiva com uma figura suspeita ou proscrita, e o subsequente conflito entre lealdade a um indivíduo e lealdade à comunidade" (GUERARD, 1966, p. 24). ${ }^{2}$

Como usual em Conrad, a condição do narrador - "o único intruso a bordo", "um tanto desconhecido inclusive de mim mesmo" e "ainda não testado numa posição da mais alta responsabilidade" 3 - dá a ver os temas que Antonio Candido depreende como sendo centrais na obra do escritor. O isolamento - a que Candido nomeia "sentimento de ilha" - é sublinhado pela repetição de termos como "a stranger" ["um intruso'] e "my strangeness" ["minha condição de intruso"] e pelo reconhecimento do narrador de que esperava "chegar a um acordo com aquele navio de que não sabia de nada, tripulado por homens sobre quem sabia muito pouco". Neófito na posição de comando e exposto a uma experiência extraordinária, o narrador, durante seu turno de vigia, verá "a segurança extrema do mar" e a normalidade serem rompidas pela aparição repentina do "corpo nu de um homem". Logo que o resgata, o narrador dá-se conta de que "[e]m plena noite, era como se me deparasse com meu próprio reflexo nas profundezas de um espelho imenso e sem luz". Escondido no camarote do comandante, Leggatt irá narrar como, em meio a uma terrível tempestade e confrontando um capitão pusilânime, havia salvado o Sephora de naufrágio. Diante do perigo iminente, o imediato vê testada sua capacidade como homem do mar e lhe cabe tomar uma decisão, embora para isso tenha acabado por matar um dos marinheiros em uma briga porque esse se negara a cooperar:

O mar não estava violento - tinha enlouquecido! É mais ou menos assim que imagino o fim do mundo; e um homem até pode, uma vez, ter a coragem de encarar a calamidade e ir até o fim - mas ser obrigado a enfrentá-la dia após dia - não posso acusar ninguém. Só respondi um pouquinho melhor que o resto. Mas - eu era um dos oficiais daquela carroça de carvão, afinal... (CONRAD, 2015, s. p.)

Esse ato, em um momento de crise, encontra a compreensão do capitão-narrador, cujo estado de tensão psicológica leva-o a quebrar algumas normas da rotina marítima. Um clima de intimidade entre ambos se instaura imediatamente e, a partir desse momento, a subida a bordo

\footnotetext{
2 Minha tradução.

${ }^{3}$ CONRAD, Joseph. O passageiro secreto. Trad. Sergio Flaksman. São Paulo: Cosac \& Naify, 2015. Disponível online em: lelivros.love/book (s. p.).
} 
desse outro estranho deflagra um processo de identificação que se materializará por meio de imagens duplicadas e especulares. Leggatt, o desconhecido recolhido, será repetidas vezes referido como "meu duplo" pelo narrador, para quem "eu era tanto quanto ele um intruso a bordo". Com um fraseado variável, mais de três dezenas de alusões a esse espelhamento se espalham pela narrativa - "meu outro eu", "meu eu secreto", "meu duplo secreto", "parceria secreta", "como uma cópia minha", "meu segundo eu", etc. -, estabelecendo uma relação de semelhança, não necessariamente física, mas moral e circunstancial entre os dois homens. Traça-se a partir daí um plano para que Leggatt possa alcançar terra firme e escapar à Justiça.

Ações furtivas, cochichos, ordens insensatas, para perplexidade de seus subordinados, tornam o capitão "suspeito de excentricidades ridículas", sobretudo quando ordena que o navio costeie para "passar o mais perto possível da terra" teoricamente em busca do terral (vento que sopra da terra para o mar), mas em realidade para deixar Leggatt o mais perto possível da costa. O jovem capitão põe em risco o navio a fim de auxiliar seu duplo, o qual, por sua vez, involuntariamente salva a embarcação ao deixar cair na água o chapéu que irá servir de referência para que o capitão-narrador emita o comando para o timoneiro realizar a manobra que irá conduzir o navio ao largo. Antes, quando o comandante do Sephora viera a bordo à procura de Leggatt e afirmara que o imediato não era "nem de longe o estilo certo de homem", o narrador reconhecera nesse juízo uma descrição de si mesmo. A necessidade de confirmar sua autoridade diante de seus homens, somada à determinação de salvar Leggatt, leva o inseguro capitão a correr riscos, apesar dos protestos de sua tripulação:

Então esqueci a partida do intruso secreto, e só me lembrei que também era um intruso total a bordo. Não conhecia aquele navio. Será que passava? Como devia ser manobrado? $($ Idem, ib.)

Submetido à prova, diante da oportunidade ele age contra o bom senso e o código marítimo. Vive o conflito entre a consciência ("era uma questão de consciência passar o mais perto possível da terra") e a infração da lei, da mesma forma que Leggatt, a bordo do Sephora. Ao fim e ao cabo, sua jornada corresponde a uma iniciação, cujo desfecho faz dele um verdadeiro capitão, em pleno domínio do seu ofício e de sua embarcação:

Nada ou ninguém em todo o mundo se interporia agora entre nós dois, lançando uma sombra que fosse em nosso caminho de conhecimento silencioso e afeto sem palavras, a comunhão perfeita entre um homem do mar e seu primeiro comando. (Idem, ib.) 
À primeira vista um típico relato de aventuras no sudeste asiático, o conto é no fundo um estudo psicológico ${ }^{4}$ sobre a relação de identificação que se estabelece entre o narrador e Leggatt, o homem que ele secretamente resgata. Encena-se aqui o tema do duplo, do homem dividido, já antes explorado por E.T. A. Hoffmann, Edgar Allan Poe, Robert Louis Stevenson e Fiódor Dostoiévski, tema que se torna, em Conrad, "uma metáfora da sociedade e da humanidade" ${ }^{5}$

Conforme salienta Albert J. Guerard, muitas das histórias de Conrad têm como protagonistas "homens inseguros e moralmente isolados que encontram e se comprometem com homens ainda mais isolados" (GUERARD, 1966, p. 48). Pequeno mundo supostamente a salvo do "dessassossego da terra", o navio flutuante na imensidão é a ilha onde seus protagonistas se acham apartados e onde mergulham na "região solitária do estresse e do conflito" ["lonely region of stress and strife"] (CONRAD, 1979, p. 145). É ainda Guerard quem argumenta que "The Secret Sharer" e Lord Jim "pertencem aos mesmos mundos ficcional e moral - em seus crimes marginais, identificações compassivas, e apreensões introspectivas" (GUERARD, op. cit., p. 27).

Primeiro grande romance impressionista de Conrad, Lord Jim se centra igualmente em um dilema humano, que envolve um jovem com uma promissora carreira no mar, cujo desejo de se tornar herói começa a esboroar quando o navio em que serve sofre uma avaria e principia a fazer água. O senso de dever de Jim o leva a tentar avaliar a extensão do estrago e pôr os passageiros a salvo nos poucos botes disponíveis. Diante de uma tempestade que se aproxima, os oficiais do Patna abandonam o navio, entregando os peregrinos muçulmanos que se destinavam a um porto no Mar Vermelho a sua própria sorte. Como resultado de seu temor compreensível mas infundado de uma catástrofe iminente, que parece incapaz de impedir, Jim (segundo capitão) toma a enigmática e repentina decisão de pular no bote do capitão. A embarcação acaba por não afundar, porém, e Jim tem de enfrentar um inquérito, vindo a perder sua certificação por ter transgredido o código dos homens do mar. As consequências daquele ato, em condições de total isolamento moral, irão repercutir no resto da sua vida.

Depois dos quatro primeiros capítulos narrados de modo objetivo, em terceira pessoa, o relato da história de Jim e do incidente do Patna será assumido pelo Capitão Charles Marlow que, ao assistir ao inquérito, se interessa por Jim e irá buscar compulsivamente recompor os fatos. Ele passa, assim, a desempenhar o papel de filtro e intérprete da maior parte da narrativa para o leitor. Perante seus ouvintes, ele se pergunta sobre as razões que o haviam motivado a "elucidar os pormenores de um deplorável incidente" (CONRAD, 1982, p. 40) e cogita que "talvez

\footnotetext{
${ }^{4}$ O jovem capitão afirma: "Isso não tem nada de conto de aventura".

${ }^{5}$ Morton Dauwen Zabel, citado por Antonio Candido (CANDIDO, 1971, nota 5, p. 75).
} 
desejasse inconscientemente encontrar [...] a explicação misericordiosa, a sombra de uma escusa convincente" (p. 40) para as ações de Jim, concluindo que:

Bem vejo agora que eu esperava o impossível, que afrontava o
mais obstinado fantasma da imaginação humana, a dúvida
inquieta que sobe como um nevoeiro, que rói em segredo como
um verme, que é mais enregelante que uma certeza de morte -
a dúvida do poder soberano que comporta uma linha fixa de
conduta. (p. 40)

Diferentemente do ponto de vista subjetivo de um narradorprotagonista e da narrativa linear de "The Secret Sharer" mas igualmente pondo em cena uma personagem diante da falibilidade e de um ato com consequências psicológicas e morais, Lord Jim combina técnicas narrativas tais como o uso do tempo, a justaposição temática (por exemplo, em dois episódios sequenciais), a progressão de efeito e a decifração simbólica à perspectiva de um narrador-testemunha. Trata-se de procedimentos bem mais complexos, postos a serviço de uma narração que elege como temas "a coragem, a vulnerabilidade especial do indivíduo imaginativo, e a relação entre atitudes públicas e privadas" (WATT, 1981, p. 281). Como peças de um quebra-cabeças, Marlow recolhe fontes e uma série de depoimentos por parte de informantes, a fim de sondar "o porquê fundamental" (CONRAD, 1982, p. 44) dos enigmas morais envolvidos na história de Jim e desvendar algo do mundo subjetivo dele.

Narrativa oral que Marlow compartilha com seus ouvintes durante um jantar dez anos após o incidente com o Patna, na primeira parte o romance se caracteriza pelo método digressivo e por descontinuidades que resultam do recurso à analepse e à prolepse sutilmente mobilizadas para criar, nas palavras de Ian Watt, "um efeito de densa particularidade impressionista em um fragmentado mas vívido presente" (WATT, op. cit., p. 300) no processo de reconstituição do sentido do ato de Jim. Nos capítulos centrais (de 20 a 35), que constituem a segunda parte, tudo impulsiona a narrativa em direção ao final, agora por meio da progressão de efeito nas cenas protagonizadas por Marlow e Stein, com a aceleração do ritmo, incidentes empolgantes e repletos de perigos, e um cenário (o assentamento de Patusan) ainda mais remoto. Os capítulos finais (de 36 até 45) contêm o relato escrito de Marlow acerca dos derradeiros acontecimentos que culminaram na morte de Jim.

Iludido pelo sonho de um feito heroico - "De seu posto, ele olhava muita vez com o desprezo do homem destinado a brilhar no meio dos perigos, [...]" (CONRAD, 1982, p. 12) - , Jim vive o dilema humano de ter de enfrentar as consequências de um ato irreparável (a traição ao código 
de solidariedade) ${ }^{6}$ e a busca de reabilitação, aparentemente possível quando lhe é oferecida uma segunda chance, em Patusan. A figura que emerge dessa experiência, no entanto, permanece envolta na névoa: a recorrência de imagens como bruma, nevoeiro, nebulosidade, véu, que impedem uma visão nítida a respeito da personagem e dos acontecimentos; o modo de construção da narrativa, que põe em cena um narrador-testemunha que precisa juntar as peças do enigma e é o filtro, ou mediação, entre o leitor e Jim; o método impressionista; a incerteza e a provisoriedade que decorrem da "ausência de uma verdade final" (WATT, 1981, p. 330).

De fato, Lord Jim aprofunda a visão conradiana do homem fragmentado ao explorar a técnica do estilhaçamento, que se materializa na multiplicação dos pontos de vista, dentre os quais Charles Marlow é apenas uma das vozes - o que põe em xeque a própria versão dos fatos envolvendo Jim que ele nos apresenta - , um complexo jogo temporal que embaralha a ordem do relato, episódios interrompidos ou encaixados, a duplicação Jim-Marlow e Jim-Brierly, todos elementos estruturais da narrativa mobilizados com a finalidade de perscrutar a natureza do mal e os abismos que habitam o mundo e a alma do homem.

"Catástrofe e sobrevivência" é mais um ensaio modelar, no qual os movimentos do crítico abrem possibilidades para a leitura de outra obra central de Conrad, na qual encontraremos uma exposição problemática do encontro desigual e assimétrico entre culturas e entre experiências históricas distintas. $\mathrm{O}$ tratamento por Conrad da alteridade radical da vida colonial, da exploração e do sofrimento coloniais resultou na ampliação dos horizontes do romance e na incorporação de novos tipos de experiência a ele. Conrad se empenhou em dar sua própria resposta literária à crise da comunidade, que se aprofundara ainda mais com o avanço do individualismo capitalista, o que tornava o ponto de vista um problema nodal na sua obra. Em Heart of Darkness (1899), em vez do estilhaçamento em diversas perspectivas, versões e vozes diferentes, como em Lord Jim (1900) e Nostromo (1904), a narrativa se organiza em torno da consciência de Marlow. Tanto em um caso como no outro, a técnica do romancista buscava expressar a multiplicidade de impressões que tomam de assalto o homem moderno e mostrar que a realidade não é uma totalidade coerente, mas uma constelação de percepções fugazes e atomizadas. A escolha do impressionismo como seu procedimento estilístico principal implicava, em última instância, uma tentativa de equilibrar dois impulsos divergentes e contraditórios - a fragmentação da vida e o esforço de imobilizá-la, a fim de procurar compreender seu sentido.

${ }^{6}$ Guerard anota: "[...] quase todo mundo pulou de algum Patna e a maioria de nós fomos obrigados a continuar vivendo, desesperada ou silenciosamente empenhados em conciliar o que somos com o que gostaríamos de ser". (GUERARD, 1966, p. 127) 
A viagem de Conrad ao Congo, como capitão de um vapor da Société Anonyme Belge pour le Commerce du Haut-Congo, forneceu os materiais para Heart of Darkness, o qual se centra na narrativa da expedição de Marlow ao coração do Congo Belga para resgatar o agente Kurtz e leválo de volta à Europa. Enquanto todos os argumentos que sustentavam a ideia da expansão colonial são testados, o relato indireto e oblíquo de Marlow sugere a absoluta impossibilidade de entender sua experiência. Adorno nos ensinou que "não se pode mais narrar, embora a forma do romance exija a narração" (ADORNO, 2003, p. 55). Assim, Marlow deve narrar, não importa quão labiríntica ou opaca sua narrativa venha a ser. A voz que nos fala de dentro da escuridão não nos permite ver com clareza; tampouco pode explicar inteiramente a natureza de sua aventura no coração das trevas. Não obstante, a fratura entre as alegações dos poderes europeus e as realidades que Marlow descobre na África emerge de seu relato, expondo a crueldade e a violência da missão civilizatória europeia naquela parte do mundo. Os nativos africanos nunca têm voz, em Heart of Darkness, e as descrições ou comentários que Marlow faz deles são eivados de preconceito e distorções. No entanto, as consequências terríveis do empreendimento colonial tanto para os colonizadores quanto para os colonizados falam por si mesmas e encontram uma voz na narrativa de Conrad. A consciência histórica de Conrad se reflete na complexa construção de um ponto de vista, na sua percepção da impossibilidade de recriar uma comunidade de destino e no despedaçamento de qualquer ideia de inteireza em um mundo apresentado à consciência como fragmentário e inapreensível. Além disso, sua narrativa parece contestar qualquer ideia ou justificativa de um projeto colonial ilustrado, seja inglês, seja europeu.

A voz incorpórea que nos fala do estuário do rio Tâmisa, onde "o mar e o céu fundiam-se sem solda aparente" (CONRAD, 2008, p. 9) é talvez uma das mais emblemáticas materializações dos problemas de que trata Antonio Candido em seu ensaio. Toda e qualquer ancoragem é posta em questão nessa narrativa de um marinheiro errante cuja vida, rotina e subsistência se vinculam ao mar, que é sua casa. Sua viagem ao coração da África lhe proporciona uma experiência pessoal e ética que, apesar de sua tentativa de dar-lhe forma narrativa, ele não pode realmente compartilhar com seus companheiros marujos, por causa da natureza do que viu e testemunhou. O Congo, a única área não reivindicada pelos principais poderes coloniais europeus, e sua exploração pelo Rei Leopoldo II evidenciam a crueldade do avanço colonial e foram escolhidos por Conrad para expor os horrores e as consequências funestas envolvidas na empresa imperial dos colonizadores brancos. A discrepância brutal entre o ideal colonizador (que Conrad abraçava) e a realidade da colonização se encarnam em Kurtz, cujo poder, combinado com a falta de controle eficaz 
sobre ele, torna-se um convite declarado para todo tipo de violência e abuso.

Na verdade, Heart of Darkness põe em xeque os argumentos que davam sustentação à ideia de expansão colonial. Os homens que tinham "singrado a vazante daquele rio [Tâmisa] rumo aos mistérios de uma terra desconhecida" para ir atrás de seus sonhos, "à caça do ouro ou perseguindo a fama, [...] levando a espada e muitas vezes a tocha", e para disseminar "a semente de comunidades de nações, os germes de impérios" (CONRAD, 2008, p. 11) acreditavam ser os portadores da luz do saber e da civilização até os confins da terra. Heart of Darkness dá a ver, porém, que a civilização não é uma condição normal e estável, mas apenas uma breve interrupção do princípio costumeiro das trevas - "vivemos no fulgor trêmulo do bruxuleio" (Idem, p. 13) - , a mesma escuridão com que se confrontaram os primeiros colonizadores romanos na Grã-Bretanha, quando ali aportaram pela primeira vez em tempos muito antigos. A Inglaterra também foi "um fim do mundo, um mar cor de chumbo", uma selva, com "frio, bruma, tempestades, doença, exílio e morte - a morte à espreita no ar, na água, nas matas" (p. 13). Seja no passado longínquo, ou no seu próprio presente, Marlow se dá conta de que não há orgulho no uso da força bruta, que é apenas "um acidente produzido pela fraqueza" alheia (p. 14).

Somente alguém que olhou para o abismo e enfrentou a tentação pelo contato com Kurtz e suas escolhas, e a deterioração moral que elas implicam, seria capaz de reconhecer como "horror" "o fascínio da abominação" (p. 14) e o sentido pleno do relato de Kurtz a respeito de sua própria experiência. Marlow parece entrever que a racionalidade da ordem capitalista, que pretende justificar a sujeição de outras terras e povos, não oculta seus aspectos mais irracionais e suas consequências fatais para todos. A mesma suspeita do progresso e dos interesses materiais que informará Nostromo mais tarde se pode ouvir nas palavras de Marlow, o qual, retrospectivamente, toma consciência das armadilhas contidas em comprometer-se com os projetos de grandeza imperial e de seus falsos pretextos humanistas. Porém, o próprio Marlow é um homem de posições muito mais dúbias e ambíguas do que pode parecer à primeira vista. A distância irônica que Conrad estabelece em relação a ele, a nãoconfiabilidade característica dos narradores em primeira pessoa, deveriam nos advertir contra tomar as afirmações e conclusões de Marlow pelo seu valor nominal. Seu relato, a bem da verdade, é cravado de inconsistências e discrepâncias e, pode-se sugerir, ainda em outra perspectiva, que a sua foi uma viagem para o coração dos escuros do ser humano.

Como um homem de seu tempo, Marlow exibe todas os preconceitos dos europeus brancos no seu tratamento dos negros. $\mathrm{O}$ discurso do império está entranhado na sua retórica, a qual responde pela imagem degradante que ele desenha dos africanos que encontra durante sua 
viagem, e pela linguagem pejorativa que usa para se referir a eles. Embora em Heart of Darkness os africanos não sejam escravizados, nem o tráfico negreiro esteja no centro dos interesses materiais em jogo ali, mas sim a exploração do marfim, é ainda o papel da Europa no Atlântico Sul e em sua economia que percorre a narrativa de Marlow sobre sua jornada rio acima. A noite que desce ao final de seu relato e a referência ao "curso de água sereno que leva aos rincões mais distantes da terra" (p. 121) traçam paralelos suficientes entre os dois rios (o Tâmisa e o Congo), entre a Europa e a África, e entre o passado e o presente, para nos permitir interpretar simbolicamente os diversos sentidos da escuridão que recai sobre a embarcação Nellie. Como sugeriu Albert Guerard, as trevas da selva congolesa, as trevas da colonização belga e as trevas insondáveis no interior de cada ser humano coalescem nas linhas finais do romance de Conrad.

Esses breves apontamentos sobre Heart of Darkess possibilitam retomar os aportes de Antonio Candido a fim de reiterar sua efetividade também para a compreensão dessa outra obra do escritor. Ali, se repõem os temas que Candido recorta nos textos que examina em seu ensaio: o isolamento físico e moral de Marlow é notório, em uma experiência cujo sentido não se explicita e que todo o tempo envolve questões éticas caras a Conrad. Seu ilhamento se constata na atipicidade da personagem, como homem do mar, no confronto com as atrocidades perpetradas por aquele que deveria personificar todo o ideal civilizatório europeu. Kurtz, o poeta, o pintor, aquele para cuja criação toda a Europa contribuíra, enlouquece, movido pelo desejo de lucro e pela desmedida "na gratificação das suas várias paixões". Kurtz é aquele que encarna, ao mesmo tempo, o homem íntegro, de sentimentos nobres, e o homem assaltado por impulsos obscuros, que transgride e se desumaniza quando se apresenta a ocasião. O encontro decisivo com Kurtz e, em última instância, com o Mal põe Marlow diante de uma projeção, daquele que também ele poderia vir a ser. Diante da "escolha de pesadelos" (p. 99) - entre a exploração e a violência perpetradas pela Companhia ou a loucura de Kurtz - , isto é, diante do abominável e da selvageria, Marlow contempla o abismo, a um passo do esfacelamento. Trata-se de seres em crise, homens divididos e surpreendidos perante escolhas cujos desdobramentos estão no plano da moral e da ética.

Enganosos são o aspecto ascético que lembra um ídolo e a postura de Buda atribuídos a Marlow, os quais podem induzir-nos a imaginar que ele é portador de ensinamentos e verdades, que sua narrativa irá desvelar. Se é possível dar uma ideia da malignidade, da truculência, da pilhagem, como, entretanto, narrar o horror? Como dar sentido a uma experiência que não cabe em palavras? Nada mais distante aqui da figura do narrador tradicional, o marinheiro comerciante cuja narrativa comporta um saber transmissível (BENJAMIN, 1985). Marlow é o indivíduo isolado a que se 
refere Walter Benjamin, cuja rememoração, a bordo da ilha flutuante ancorada no estuário do Tâmisa, malogra em iluminar para seus ouvintes algum sentido para a experiência vivida.

Sua narrativa, carregada de tensão dramática, é vazada em linguagem impressionista, marcada pelo jogo entre claro e escuro e recoberta, assim como a paisagem africana, de uma névoa permanente, que tudo encobre. Lançando mão de uma técnica que Ian Watt definiu como "delayed decoding" (decodificação diferida) (WATT, 1981), a narração se alonga, retarda explicações, envolve cenas em denso nevoeiro, joga sombras sobre seus personagens, dilui contornos, apaga referências, querse indecifrável. $O$ tratamento descritivo opera por sugestão e faz valer a advertência do Diretor de que Marlow não era como os outros homens do mar, cujos relatos "têm uma simplicidade direta cujo significado total cabe na casca de meia noz". Marlow, ao contrário, é um narrador atípico:

[...] para ele o significado de um episódio não residia no seu miolo, como um caroço, mas do lado de fora, envolvendo a narrativa que o expõe só como um brilho tênue que provoca um certo ofuscamento, à semelhança de um desses halos de bruma que às vezes se tornam visíveis graças à luz espectral da lua. (CONRAD, 2008, p. 12)

Marlow é simultaneamente sujeito e objeto de sua história. O que diz não é sopesado com lucidez, mas soa aleatório e perplexo, deixando contradições sem resolução e permitindo que elementos menos conscientes venham à tona, na sua tentativa de dar sentido às suas percepções. $\mathrm{O}$ método narrativo de Conrad cria uma clivagem entre o narrador e seus ouvintes, a qual expõe a dificuldade de Marlow de contar toda a história. A prática impressionista atrasa a ação e Marlow, como consciência central do relato, substitui ações por impressões e reflexão, mesclando análise à narrativa de uma experiência real vivida. A dificuldade crescente de simular verdades "universais" leva Conrad à desintegração dos métodos realistas, predominantes no romance do século XIX. Dissolve-se a visão realista da vida cotidiana, e a representação se torna problemática, oblíqua, indireta.

Enquanto "aventura" e "exotismo" pareceriam ser, à primeira vista, o material que organiza o romance de Conrad, e Antonio Candido chama atenção para a importância desses elementos da arte conradiana, a análise do crítico irá escavar suas camadas subjacentes e o que se oculta por trás do aparente exotismo, do "tratamento descritivo" e da "elaboração impressionista" de suas narrativas. Do breve artigo de 1957 iria resultar, alguns anos depois, uma leitura aguda das questões de conteúdo e forma da produção do escritor.

$\mathrm{Na}$ versão desenvolvida em Tese e antítese, a "aventura" e o "exotismo", escolhas lexicais de Antonio Candido para intitular o artigo 
para o Suplemento Literário, foram substituídas por "Catástrofe e Sobrevivência", com o acréscimo de uma epígrafe que reproduz dois versos de Murilo Mendes: "Para a catástrofe, em busca / Da sobrevivência, nascemos". Publicado em primeira edição no ano de 1964, o livro de Candido teve mais duas edições em 1971 e 1978. Diante dessas datas, a mudança do título do ensaio não parece casual. Tratava-se, sugestiva e indiretamente, de pensar, pelo viés dos textos literários analisados, questões prementes do seu próprio presente histórico, durante os quais as noções de catástrofe e de sobrevivência se tornavam nodais para, no caso da primeira, definir o momento que se vivia, com o golpe de 64, e, da segunda, lançar uma palavra de ordem crucial para os opositores da ditadura. A catástrofe do empreendimento colonial, na obra de Conrad, e as escolhas éticas que ela exigia de todos os envolvidos permitiam, ainda que sugestiva e indiretamente, fornecer elementos para refletir sobre essa outra catástrofe que se abatia sobre os brasileiros naquele momento histórico. Eram também eles homens surpreendidos pelo que Candido denomina a "ocasião", que viria a exigir deles escolhas de ordem política, mas também moral e ética. O crítico expõe com clareza e objetividade como "concepção e técnica se fundem intimamente" (CANDIDO, 1971, p. 91) nas diversas narrativas que analisa, assim como aponta a necessidade imperiosa e urgente de resistir e sobreviver ao Mal, ao abominável, que se impõe às personagens conradianas, sob pena de perda da integridade e de divisão do ser.

Se a tração crítica desse ensaio é indiscutível, arrisco a sugerir que ele representa ainda, mesmo que de modo discreto à maneira de seu autor, uma intervenção e um posicionamento diante da ocasião, valendo-me de um de seus termos. Tratava-se de dar voz à experiência concreta do crítico em seu presente e de assumir uma posição frente a ele. ${ }^{7}$

\section{Referências bibliográficas}

ADORNO, Theodor W. "Posição do narrador no romance contemporâneo". In: Notas de literatura I. Trad. Jorge de Almeida. São Paulo: Duas cidades; Ed. 34, 2003, p. 55-63. [The Position of the Narrator in the Contemporary Novel. In: Notes to Literature. Trans. Shierry Weber Nicholsen. New York: Columbia University Press, 1991, v. 1, p. 30-6].

CANDIDO, Antonio. "Catástrofe e sobrevivência”. Tese e antítese. 2a. ed. São Paulo: Companhia Editora Nacional, 1971, p. 59-93.

\footnotetext{
${ }^{7}$ Nota de rodapé: quando escolhi tratar desse texto, no mês de agosto de 2018, não imaginei que os dois termos que dão título ao ensaio de Antonio Candido passariam também a descrever nosso presente e exigir de nós, mais uma vez, a capacidade de sobrevivência. Sequer suspeitei da sua assustadora, estarrecedora atualidade.
} 
BENJAMIN, Walter. "O narrador. Considerações sobre a obra de Nikolai Leskov". Obras escolhidas. Magia e técnica, arte e política. Trad. Sergio Paulo Rouanet. São Paulo: Brasiliense, 1985, p. 197-221.

CONRAD, Joseph. Coração das trevas. Trad. Sergio Flaksman. São Paulo: Companhia das letras, 2008.

CONRAD, Joseph. Lord Jim. Trad. Mário Quintana. São Paulo: Abril cultural, 1982.

CONRAD, Joseph. O passageiro secreto. Trad. Sergio Flaksman. São Paulo: Cosac \& Naify, 2015.

CONRAD, Joseph. "Preface". In: The Nigger of the 'Narcissus'. New York: W. W. Norton, 1979, p. 145-48.

CONRAD, Joseph. "The Secret Sharer". In: CHATMAN, Seymour. Reading Narrative Fiction. New York: Macmillan, 1993, p. 388-415.

GUERARD, Albert J. Conrad the Novelist. Cambridge, Mass.: Harvard University Press, 1966.

WATT, Ian. Conrad in the Nineteenth Century. Los Angeles: University of California Press, 1981.

WATT, Ian. "The Secret Sharer": introduction. Essays on Conrad. Cambridge: Cambridge University Press, 2000.

Sandra Guardini Vasconcelos é professora titular de Literaturas de Língua Inglesa da Faculdade de Filosofia, Letras e Ciências Humanas da Universidade de São Paulo. Autora de Puras Misturas (1997), Dez Lições sobre o Romance Inglês do Século XVIII (2002) e A Formação do Romance Inglês: ensaios teóricos (2007), que recebeu o Prêmio Jabuti 2008 na categoria Teoria /Crítica Literária. Participou dos Projetos Temáticos FAPESP "Caminhos do romance no Brasil: séculos XVIII e XIX" (2004-7) e "A circulação transatlântica dos impressos: a globalização da cultura no século XIX" (2011-15); coordenou o projeto "Deslo-camentos, descentramentos: romances sem fronteiras" (AP$\mathrm{R}$ /SPRINT-FAPESP), desenvolvido com pesquisadores da Universidade de Warwick. Atualmente, coordena o Laboratório de Estudos do Romance e o projeto "The Global Novel", com professores da Universidade de Surrey. É curadora do Fundo João Guimarães Rosa (IEB-USP) e pesquisadora 1A do CNPq. Contato: sgtvasco@usp.br

ORCiD: https:// orcid.org/0000-0002-7222-5802 